\title{
Telephone consulting in primary care: a triangulated qualitative study of patients and providers
}

\author{
Brian McKinstry, Philip Watson, Hilary Pinnock, David Heaney and Aziz Sheikh
}

\begin{abstract}
Background

Internationally, there is increasing use of telephone consultations, particularly for triaging requests for acute care. However, little is known about how this mode of consulting differs from face-to-face encounters.
\end{abstract}

Aim

To understand patient and healthcare-staff perspectives on how telephone consulting differs from face-to-face consulting in terms of content, quality, and safety, and how it can be most appropriately incorporated into routine health care.

Design of study

Focus groups triangulated by a national questionnaire. Setting

Primary care in urban and rural Scotland.

\section{Method}

Fifteen focus groups ( $n=91)$ were conducted with GPs, nurses, administrative staff, and patients, purposively sampled to attain a maximum-variation sample. Findings were triangulated by a national questionnaire.

\section{Results}

Telephone consulting evolved in urban areas mainly to manage demand, while in rural areas it developed to overcome geographical problems and maintain continuity of care for patients. While telephone consulting was generally seen to provide improved access, clinicians expressed strong concerns about safety potentially being compromised, largely as a result of lack of formal and informal examination. Concerns were, to an extent, allayed when clinicians and patients knew each other well.

\section{Conclusion}

Used appropriately, telephone consulting enhances access to health care, aids continuity, and saves time and travelling for patients. The current emphasis on use for acute triage, however, worried clinicians and patients. Given these findings, and until the safe use of telephone triage is fully understood and agreed upon by stakeholders, policymakers and clinicians should consider using the telephone primarily for managing follow-up appointments when diagnostic assessment has already been undertaken.

\section{Keywords}

confidentiality; health care quality, access; physician-patient relations; telephone consulting.

\section{INTRODUCTION}

There is increasing international policy emphasis on timely patient access to health care..$^{1-3}$ In an attempt to improve quality of care against an increasing workload, clinicians are using innovative methods of delivering care, including expansion of the use of telephone consulting. ${ }^{4}$ In several countries, out-ofhours requests for medical treatment or advice are routinely telephone triaged, ${ }^{5,6}$ and increasingly this is also the case with requests for 'same-day' appointments. ${ }^{7,8}$ Patients have had little say in the introduction of telephone consulting.

A number of studies have demonstrated that telephone consultations are shorter than face-toface consultations, ${ }^{7,8}$ and may be time efficient in managing continuing illness. ${ }^{9,10}$ These apparent time savings may be offset in the case of acute consultations by subsequent increased reattendance as, for example, demonstrated by the current researchers' previous trial and by others reported in this journal. ${ }^{11,12}$ Furthermore, the safety of telephone consultations remains a major concern. ${ }^{13}$

It is not clear how patients, clinicians, and administrative staff (who typically control access to

B McKinstry, $M D$, FRCPE, FRCGP, reader in primary care research; $\boldsymbol{P}$ Watson, $P h D$, research fellow; $H$ Pinnock, $M D$, FRCGP, senior research fellow; A Sheikh, MD, FRCGP, professor of primary care research and development, Centre of Population Health Sciences: General Practice Section, University of Edinburgh, Edinburgh. D Heaney, MA, senior research fellow, Centre for Rural Health, University of Aberdeen, Aberdeen.

Address for correspondence

Brian McKinstry, Centre of Population Health Sciences: General Practice Section, University of Edinburgh,

Edinburgh, Scotland, EH8 9DX.

E-mail: brian.mckinstry@ed.ac.uk

Submitted: 15 August 2008; Editor's response: 7 October 2008; final acceptance: 11 December 2008.

OBritish Journal of General Practice

This is the full-length article of an abridged version published in print. Cite this article as: Br J Gen Pract 2009; DOI: 10.3399/bjgp09X420941. 
different consultations) view in-hours telephone consultations in terms of access, safety, continuity, and holistic care, or for which types of problem and presentation they are best suited. This study sought to explore and understand how healthcare staff and patients use telephone consulting and, specifically, how they see this differing from face-to-face consulting in terms of content, safety, and quality. The study aim was to progress understanding about the contexts in which telephone consulting is most appropriately used.

\section{METHOD}

\section{Focus groups}

Separate focus groups of GPs, nurses, administrative staff (receptionists and practice managers) and patients were conducted.

Recruitment. Focus groups were conducted in both urban (Lothian) and rural (Highland) regions of Scotland, as it was anticipated that participants in different regions may hold different views about telephone consulting. GPs, practice nurses, administrative staff, and patients were approached with an aim of recruiting a maximum-variation sample representing a range of ages, rurality, sex, and experience of and views about telephone consulting. Parents of young children were sought, who often seek 'same-day' appointments. ${ }^{11}$

Thirty-nine practices were purposively selected in Lothian and Highland for recruitment of healthcare staff on the basis of four criteria: training status, practice size, deprivation indices, and rurality. To aid purposive sampling, practice staff completed a screening questionnaire designed to capture their current use of telephone consulting, views regarding its appropriateness for specific problems, and its impact on workload. The researchers took advantage of a conference of widely scattered remote and island-based GPs to recruit participants using the same screening exercise.

Patient recruitment was conducted in seven practices, purposively selected, using national databases, to represent different levels of deprivation, size, and rurality. ${ }^{14}$ A screening questionnaire similar to that used for staff was posted to the most recently consulting 15 or 30 (depending on practice size) patients. Electronic mapping aids were used to establish the distances that participating rural patients lived from their general practice.

Data generation. The separate focus groups were held in convenient locations (for example, health centres, community centres, and hotels). A literaturebased topic guide was used, where necessary, to

\section{How this fits in}

Telephone consultations are increasingly being used to improve access to healthcare. However, very little is known about how they differ from traditional

face-to-face clinical encounters in terms of content, quality, and safety. This

study revealed that, while telephone consultations were seen as convenient for

both patients and clinicians, there were concerns about patient safety,

particularly when used for diagnostic triage mainly by urban clinicians.

Telephone consulting was considered more suited to follow-up and

management of long-term conditions where an initial diagnostic assessment

has been made and, if employed in this way, could facilitate continuity of care and save travel time and costs for patients.

stimulate relevant free-flowing discussion. This was modified during pilot focus groups $(n=3)$ and during the course of the study to incorporate arising themes. Discussions were audio recorded, transcribed verbatim, and entered into NVivo 7 . Concurrent data analysis allowed emergent themes to be incorporated and explored in subsequent interviews. Data generation continued until saturation occurred. ${ }^{15}$

\section{Analysis}

A framework approach was used, ${ }^{16}$ as this is particularly useful for applied or policy-relevant qualitative research and makes use of the efficiency gained through relatively structured data generation, based on preset aims. Analysis involved immersion in the data, and identification of a thematic framework based partly on the research questions and data from the responders. Subthemes were charted into overarching themes and used to define concepts, identify important phenomena, and allow associations to be drawn and explanations of the data to be considered.

Two researchers (a psychologist and a GP) independently analysed data and agreed coding allocations, with a sample of these jointly agreed codes being independently checked by researchers (a GP and a social scientist). Deviant cases and possible conflicting interpretations were actively sought to express a wide range of views. The analysis was fed back to a multidisciplinary group of clinical and lay participants to check agreement with findings and assist interpretation.

\section{Triangulation}

Questionnaire design. A national questionnaire was used to corroborate the focus group findings. Four questionnaires (patient, GP, nurse, and administrative staff) were constructed on the basis of focus group findings and modified after two phases of piloting. These contained Likert-style questions about general attitudes to telephone consulting and if and how this 
Table 1. Characteristics of focus group participants.

\begin{tabular}{|c|c|c|c|c|c|c|}
\hline Participant group & Invited & $\begin{array}{c}\text { Returned } \\
\text { screening } \\
\text { questionnaire }\end{array}$ & $\begin{array}{c}\text { Actually } \\
\text { participated }\end{array}$ & $\begin{array}{c}\text { Number } \\
\text { of } \\
\text { groups }\end{array}$ & $\begin{array}{l}\text { Age } \\
\text { range, } \\
\text { years }\end{array}$ & $\begin{array}{l}\text { Sex, } \\
\text { M/F }\end{array}$ \\
\hline \multicolumn{7}{|l|}{ Lothian } \\
\hline GPs & 140 & 34 & 14 & 2 & $37-61$ & $9 / 5$ \\
\hline Nurses & 61 & 18 & 7 & 1 & $32-60$ & $0 / 7$ \\
\hline Admin staff & 62 & 17 & 17 & 3 & $31-51$ & $0 / 17$ \\
\hline Patients & 127 & 38 & 17 & 3 & $19-85$ & $5 / 12$ \\
\hline \multicolumn{7}{|l|}{ Highland } \\
\hline GPs & 34 & 11 & 11 & 2 & $26-57$ & $5 / 6$ \\
\hline Nurses & 11 & 7 & 7 & 1 & $32-54$ & $0 / 7$ \\
\hline Admin staff & 18 & 10 & 2 & 1 & $44-67$ & $0 / 2$ \\
\hline Patients & 70 & 35 & 16 & 2 & $18-83$ & $8 / 8$ \\
\hline Total & & & 91 & 15 & & \\
\hline
\end{tabular}

differed in terms of safety, content, and quality from face-to-face consulting.

Construction and piloting of the questionnaire. The questionnaire was based on the themes that arose in the focus groups. Each questionnaire was piloted

Table 2. Mapping of themes.

\begin{tabular}{ll} 
Theme & Category \\
\hline Safety/quality of care & Clinical responsibility \\
& Knowing the patient \\
& Training \\
Importance of seeing the patient & Concerns whether the patient is able \\
to describe symptoms adequately \\
Concerns the doctor fails to ask \\
something important \\
Confidentiality/misidentification \\
Appropriate use of telephone consulting \\
Perceived riskiness of telephone consulting \\
Fear of litigation \\
Safety netting \\
Continuity of care \\
Use of emergency face-to-face consulting \\
as alternative to telephone consulting \\
\hline Perception of telephone consulting as \\
facilitator or barrier to access \\
Demographically disadvantaged \\
Demographically advantaged \\
Patient choice \\
Negotiation \\
Urban/rural differences \\
\hline Access to care & Views on overall impact on workload \\
Impact on patients' time
\end{tabular}

on 10 members of each group for comprehension and usability, and the wording subsequently altered and retested before questionnaires were dispatched.

Recruitment. Every fifth Scottish GP practice $(n=$ 206) was systematically selected for the purpose of staff recruitment (excluding those that took part in the focus groups). Of these, 158 practices agreed to accept the questionnaires. In total, 910 questionnaires were sent to GPs, nurses, and administrative staff with two reminders. Where possible, the actual names of practice staff were obtained, so a personal letter could be sent. As an incentive, participants were invited to nominate a charity when replying to the questionnaire, to which a donation would be made, with the donation going to the charity with the largest number of nominations. In order to boost the response from practice staff, a £20 token was subsequently offered, but this resulted in relatively few additional responses.

Ten practices, chosen to reflect Scottish demography and telephone use, sent questionnaires to 600 patients who had recently consulted with their doctor.

Analysis. Descriptive analysis was undertaken using SPSS (Version 12). The $\chi^{2}$ test was used to undertake a priori agreed comparison of responses between responder groups, and between patients of different ages and sex.

\section{RESULTS}

\section{Recruitment to focus groups}

Staff from 30 of $35(86 \%)$ practices that were approached completed screening questionnaires. Ten focus groups were conducted with healthcare professionals and administrative staff, and five with patients (Table 1). Those responding did not significantly differ demographically from nonresponders. The participants represented a range of ages, social backgrounds, rural/urban location, and views on and experience of telephone consulting.

\section{Key themes identified}

Responses were initially coded into 30 categories which were grouped into five over-arching themes: safety and quality of care, access to care, impact on workload, content of telephone consulting, and technical/organisational issues (Table 2).

Some of the findings, namely the difficulties that language or hearing-impaired patients have with telephone consulting, ${ }^{17}$ technical difficulties with getting through on the phone to doctors' surgeries, ${ }^{18}$ reduction in opportunistic screening, ${ }^{11}$ and patients' unhappiness with receptionists requesting their 


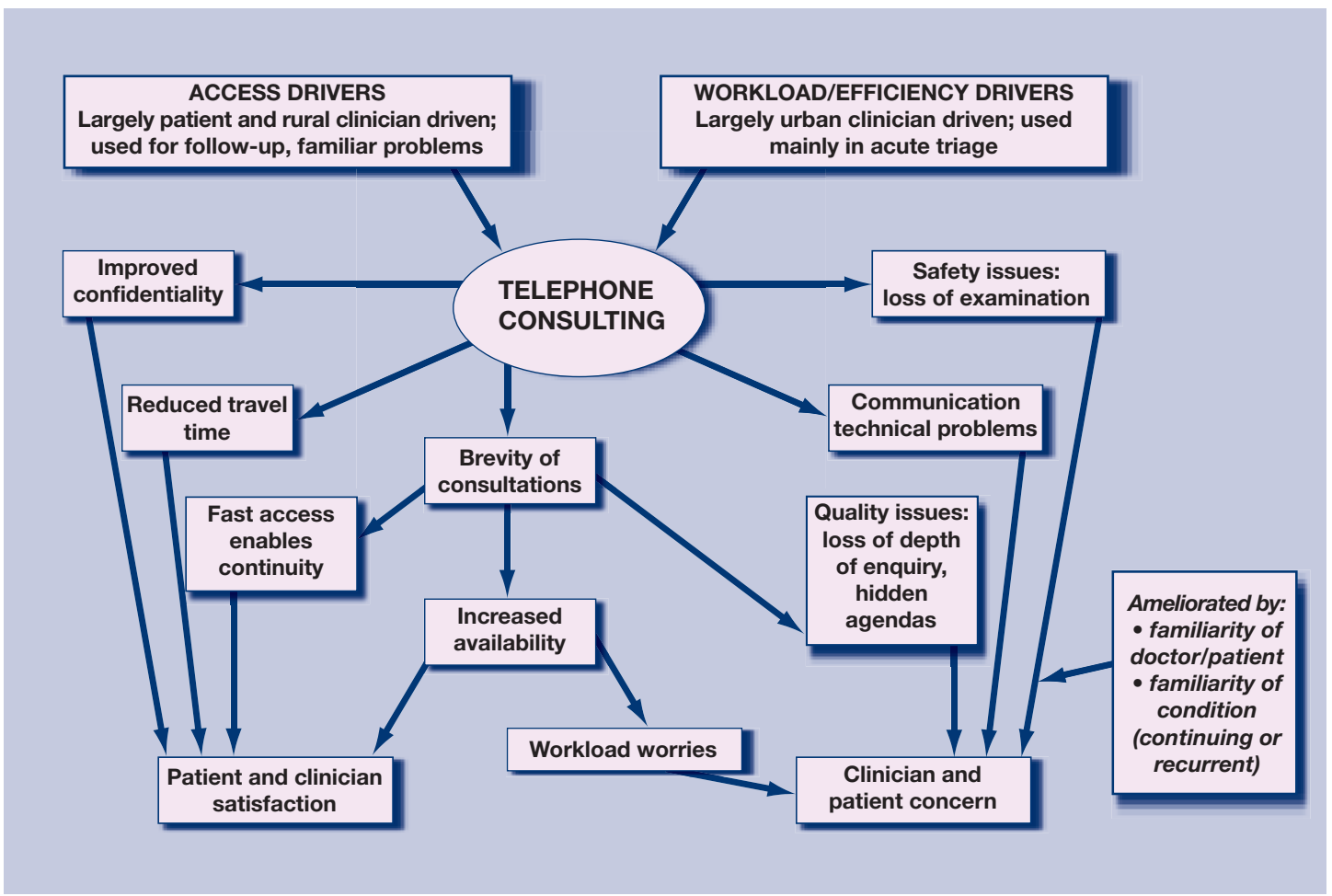

Figure 1. Drivers for and impact of telephone consulting.

medical details, ${ }^{19,20}$ confirmed previous reports in the literature, and are therefore not discussed further. Instead, this study will focus on several novel insights in relation to the drivers behind the adoption of and use of telephone consulting, access to care, and safety and quality of care. Figure 1 summarises the relationships between drivers for and the various impacts of telephone consulting.

\section{Reasons for adopting telephone consulting}

There was a discourse mainly among urban clinicians and administrative staff, that patient demand for appointments was 'insatiable', compounded by a perception of little flexibility in their own working lives. Telephone consulting was seen as a necessary compromise to achieve access targets. Administrative staff perceived that telephone consulting potentially avoided conflict with patients as they could provide an alternative, even if face-toface appointments were full. However, several GPs expressed concern that it further increased access to an already overstretched service, reduced control over their workload, and postponed rather than resolved problems:

'We were getting overwhelmed without it [telephone consulting] so the practice moved towards it to save the sanity of the afternoon doctor and it has improved the afternoon situation.' (urban male GP, aged 62 years)

'One of the things I am fearful about is it would be another way of contacting us and we are already too readily available.' (urban male GP, aged 43 years)

\section{Access to care}

Patients perceived difficulty in getting suitable appointments, particularly with their preferred doctor, but saw GPs as being busy and there was a discourse around not wanting to 'waste the doctor's time'. They reported that clinicians appeared to provide access to telephone consulting more readily than to face-to-face appointments. Full-time workers, parents, poorly mobile patients, and those living at a distance found the facility useful. However, there was a clear perspective from administrative staff and patients that clinicians' time was more precious than patients', and that consultations happened at times to suit the clinician:

'We get a lot of patients saying: "when will she phone me back?". Well she has to prioritise her calls in medical emergencies so she will call you when she can. "Well tell her to make it after 2.30 because I am going out!" We can't do that, you need to give the contact number to suit the nurse practitioner.' (urban female receptionist, aged 63 years)

'The doctor is going to phone you back, sitting there beside the phone and frightened to go to the loo, frightened to go somewhere else in case 
the phone goes and they don't get the call back.' (urban female patient, aged 68 years)

\section{Rural issues}

In rural areas, for both patients and staff, the telephone was used to overcome distance. Enhanced continuity of care was seen as an advantage, and it was not unusual for patients to maintain long-distance relationships by phone (for example, when working away or on holiday):

\section{'I can get ... some guy phoning me ship-to-shore to just off Gambia! He asks you about his diarrhoea!' (rural male GP, aged 39 years)}

Rural patients used the telephone to determine if a visit to the doctor was really necessary (a reversal of the roles in urban settings), citing saving doctor time as a reason, but also saving themselves a long journey:

'I think the simple answer is time, where I live is ... 25 miles away from the ... medical centre. The doctor comes down once a week, if I go and see the doctor ... I invariably have to wait and it may be 15 minutes it may be less. My time is actually valuable and I feel that if some arrangement was made whereby a doctor rang me, at least she can give me a time I can talk to her, that would be a huge improvement.' (rural male patient, aged 62 years)

However, telephone lines and mobile signals were less reliable in rural than urban areas, and prescribing by telephone posed problems in remote areas where the dispenser was practice based and prescription collection took as long as a visit to the doctor.

\section{Safety and quality of care}

Loss of visual cues. For clinicians, the major drawback of telephone consulting was the loss of insight derived from 'informal' global examination in face-to-face consulting, which helped them establish quickly who may be seriously ill. One patient described how her mother who was seriously ill failed to describe her symptoms adequately, whereas if the doctor had seen her he would have recognised immediately how ill she was:

'Well I am talking from personal experience of my mother who phoned and was prescribed cocodamol and she actually had chronic leukaemia which had gone to acute leukaemia, so by that stage she didn't need co-codamol she needed something far greater than that, but being the kind of person she was she wouldn't pursue this, she didn't want to be a bother so there is that side of this phone consulting too that has got to be looked at.' (rural female patient, aged 60 years)

Patients and clinicians both cited loss of bodylanguage cues during telephone consultations as important, particularly in the assessment of mental health. Although non-verbal auditory cues were seen as possibly helpful, these were typically regarded as a poor substitute, although not all agreed:

'You could also read the other if you are face-toface, whoever you were talking to would be able to read your physical signs as well as what you were saying, which you would not necessarily be able to do over the phone and actually would then possibly lead the questioning down a completely different avenue.' (rural female patient, aged 35 years)

\section{However:}

'Yes, we are risk takers. We rely on the fact that we can pick up the underlying message behind what somebody is saying, often you will be picking up unconsciously different resonances from what the patient is telling you, and of course if you know the patient you are adjusted to that anyway. You do use it, you can tell from somebody's voice if they are depressed.' (urban male GP, aged 57 years)

Need for heightened verbal skills. The absence of visual cues put an onus on clinicians to be sure that a comprehensive history is taken, and on patients to be sure that symptoms are accurately described. Patients described anxiety about the responsibility of 'getting it right', especially for a child. A brief physical examination was seen as superior to any number of words:

'Especially if you are panicking and you forget to tell them something that could be relevant. The doctor can examine and see what is wrong, whereas if we examined we might miss something.' (urban female parent, aged 25 years)

Administrative staff described often making decisions on access based on how ill or distressed a patient appeared at the desk, and reported unease at having to make priority-related decisions with patients they could not see:

'I think it could be quite hard for some people to decide; will a telephone consultation do, will I 
need to go and see the doctor, should I call the doctor to my home, and I think for a lot of people that is quite a hard process to go through when you are ill.' (rural female patient, aged 55 years)

Knowing the doctor and the suitability of the mode of consultation. Many of the patient and clinician concerns were allayed when the parties knew each other. Clinicians were more confident that their patient would give an accurate history and adopt a 'sensible' approach to self-management, and patients believed their clinician knew their history well enough to make safe decisions, particularly if the presenting problem was a recurrent one:

'I would much rather take that risk because I know they [current rural GPs] know the children, whereas being in a practice in the city they know you when they see you but otherwise you are just a number, so I think the size of the practice and the fact that the doctors/nurses/midwifes know you makes a big difference.' (rural female patient, aged 35 years)

Most participants agreed that telephone consulting provided an appropriate platform for 'simple' problems, most frequently taken to mean a follow-up of an ongoing problem, test result, or recurrence of a familiar problem. Participants were generally wary about managing by telephone potentially serious and unstable conditions, such as fever in infants or severe headache, and presentations that required visual examination, such as rashes. GPs from remote areas commented that, through necessity, all problems may have to be initially managed by telephone. Concerns arose in urban areas, often due to appointment unavailability or 'late' calls, when there was a mismatch in expectation when patients wanting a face-to-face encounter found themselves managed by telephone. In these circumstances, often patient and clinician felt unhappy about the quality and/or safety of the service offered:

'Sometimes when you speak to someone on the phone and they are angry and desperate to be seen and you get that idea right away and if you try to say, "OK we will see you if you really feel you need to be seen", then they seem to calm down. It is sometimes if they think they are not going to be able to get seen.' (urban female nurse, aged 38 years)

'What I find quite interesting, quite challenging is that I find the more experienced you are the more difficult it [telephone consulting] becomes.
I find with the younger ... practitioners [they] seem to telephone triage a lot more because I think they are perhaps unaware of the pitfalls. It is only as you go by and you see the disasters that you are aware of what is out there that you think "wait a minute it is very serious"; we are risk taking all the time. I find sometimes increasingly uncomfortable, we are taking a bit of a gamble and doing all that $99 \%$ of the time.' (urban male GP, aged 49 years)

Quality of care. Both patients and clinicians saw a telephone consultation as something that they would expect to be brief, focused on one problem, and unlikely to explore psychosocial dimensions. Faceto-face consulting, however, came with expectations of a certain amount of time to be taken regardless of the presenting problem, and permitted the development of complexity in a way that telephone consultations did not. In addition, purely social speech was also uncommon, which some patients and clinicians regretted:

'The advantage of the [face-to-face] consultation is you both set aside 5 or 10 minutes, you trouble yourselves to be there, the door is closed and you have got each other's full attention for 5-10 minutes. On the telephone, none of these things necessarily apply.' (urban male GP, aged 50 years)

The presentation of hidden agendas was considered rare on the telephone. However, one doctor, to some hilarity within the group, indicated that too often GPs were in the business of ' ... not so much as picking up minimal cues, but blatantly ignoring maximal cues, trying to bring in trailing problem number three or whatever [laughter]'.

\section{Triangulation}

Of the 1510 questionnaires distributed via the 168 participating practices, 582 (39\%) responded. In terms of size and deprivation, ${ }^{21}$ participating practices were similar to the national profile (Appendix 1).

The questionnaire findings largely mirrored the conclusions from the focus groups (see Appendices 2-7 for selected findings). GPs used telephone consulting frequently, $90 \%$ using it for brief advice and $50 \%$ for follow-up consultations. Practice nurses used it less frequently. In terms of safety, more than $70 \%$ of clinicians and $60 \%$ of patients agreed that they were concerned that clinicians would be more likely to make a wrong/inaccurate diagnosis if they were telephone consulting than when consulting face-to-face. However, most participants agreed that 
if they knew each other, this would ease their concern. Older patients (>65 years) were more likely than younger patients to believe that they would be receiving 'second best' if they were offered a telephone consultation, and that they would not be able to describe their symptoms, or understand or recall the advice they were given as well on the telephone compared with face-to-face (all $P<0.01$ ). Telephone consulting was seen as particularly unsuitable for patients with hearing or speech impairment, cognitive impairment, and where doctor and patient did not speak the same language. Despite this, few professional participants were aware of interpretive aids for these groups

\section{DISCUSSION}

\section{Summary of main findings}

This study shows that telephone consulting is seen as an enhancement of normal access to care by both healthcare staff and patients. However, both groups expressed safety concerns stemming largely from the loss of formal and informal examination, although these were perceived as, to an extent, being ameliorated by familiarity between patients and clinicians and the condition (for example, a follow-up or recurrent condition).

Despite previous research suggesting that telephone consulting may not save time, ${ }^{11,12}$ urban clinicians mainly used telephone consulting to triage acute presentations, often necessitating uncomfortable decisions (for both them and the patient) in the absence of examination. While wellestablished acute triage systems were often described by participants, it was rare for practices to have set up formal systems to provide routine telephone follow-up appointments to deal with continuing problems. In contrast, rural GPs used telephone consulting mainly to overcome physical distance and to maintain continuity.

\section{Strengths and limitations of the study}

The use of screening questionnaires ensured a range of experience and views about telephone consulting. Discordant views were sought, and data generation was continued until saturation occurred..$^{15}$ The potential influence of the researchers' own healthcare and sociological backgrounds on data interpretation is recognised; however, the findings and interpretation were presented to participants for validation, by post and at a multidisciplinary workshop, and participants were largely in agreement.

Given the questionnaire response rate, results from this triangulation exercise must be treated with caution. Notwithstanding this limitation, it is reassuring that the responses were in agreement with the focus group findings and also reflect the views expressed in other surveys. ${ }^{19,22}$

\section{Comparison with existing literature}

Concerns about the safety of telephone consulting are not new. ${ }^{13,23}$ Although trials of telephone triage have not demonstrated excess serious outcomes, they have not been powered to detect such rare events. ${ }^{24}$ However, it is possible that the patient and professional concerns are unfounded.

The perception that safety was enhanced by knowing the patient or clinician was strongly held by all types of participants, both in focus groups and in the questionnaire responses. However, the present study was unable to find any evidence that such knowledge actually improves safety. There is a potential paradox in that familiarity may actually reduce safety, in that doctors will make assumptions about and take chances with patients they know well, in a way they would not with patients whom they do not know well.

The working differences between rural and urban doctors have been previously described and are partly due to differences in demand, but also because they construct their time differently: the former adhering to a more traditional concept of 24hour availability and practice location near doctors' homes. ${ }^{25}$ While appointment systems have effectively partitioned 'free' and work time for urban clinicians, this may have contributed to the perception of pressure 'in-hours'. However, rather than further increase their availability, alternatives to traditional consulting have been sought, expressed in the rhetoric of 'efficiency'.

\section{Implications for future research and clinical practice}

Whether or not the concerns about the safety of telephone triage expressed by the participants in this study are ultimately justified, it would seem appropriate that service planners should, for the present, consider employing telephone consulting less for diagnostic triage and more for follow-up and management of long-term conditions where an initial assessment or diagnosis has been made. ${ }^{26,27}$ In addition, for low-risk or recurrent conditions that familiar to both doctor and patient, patients should be informed of the suitability and availability of telephone consulting to manage such problems. These changes might save time, reduce the pressure on appointments, and obviate the need for the much-disliked receptionist triage, and should be the subject of future research. Medical educators need to include specific strategies for compensating for the limitations of telephone consulting in their training programmes. 
Given that simple visual global assessment was perceived as important in determining the severity of a presentation, it may be that in the future highquality video consulting may allow more effective remote triage. However, such developments will require careful evaluation.

More work is clearly needed to enhance remote interpretative facilities for patients with hearing or speech impairments, learning disabilities, or poor English, who are clearly disadvantaged by telephone consulting.

\section{Funding body}

This study was funded by the Chief Scientist Office of the Scottish Government (CZH/4/303). Brian Mckinstry and Hilary Pinnock are supported by the Chief Scientist Career Scientist programme. The funder had no input into the design or running of the study, in writing the paper, or in the decision to submit for publication

\section{Ethical approval}

Ethical approval was obtained from Lothian Multicentre Research Ethics Committee (ref 06/MRE10/27) and local research and development offices

\section{Competing interests}

The authors have stated that there are none

\section{Acknowledgements}

We are grateful to the Scottish Primary Care Research Network for their help with recruitment of practices, all the clinicians and patients who took part, Jon Dowel for his help with project design, and Sue Gregory, Karen Fairhurst, and Marilyn Kendall for their help with the final manuscript.

\section{Discuss this article}

Contribute and read comments about this article on the Discussion Forum: http://www.rcgp.org.uk/bjgp-discuss

\section{REFERENCES}

1. Institute of Medicine, Committee on Quality of Health Care in America. Crossing the quality chasm: a new health system for the 21st century. Washington DC: National Academy Press, 2001.

2. Department of Health. Building on the best: choice, responsiveness and equity in the NHS. London: Department of Health, 2003.

3. Rae D. Getting better value for money from Sweden's healthcare system. OECD Economics Department Working Papers, No. 443. Paris: OECD Publishing, 2005.

4. Car J, Sheikh A. Telephone consultations. BMJ 2003; 326(7410): 966-969.

5. Olesen F, Jolleys JV. Out-of-hours service: the Danish solution. BMJ 1994; 309(6969): 1624-1626.

6. Van Uden CJT, Nieman FHM, Voss GB, et al. General practitioners' satisfaction with and attitudes to out-of-hours services. BMC Health Serv Res 2005; 5: 27.

7. Oldham J. Telephone use in primary care. Programme to shape demand has been started in several practices. BMJ 2002; 325(7363): 547.
8. Jiwa M, Mathers N, Campbell M. The effect of GP telephone triage on numbers seeking same-day appointments. Br J Gen Pract 2002; 52(478): 390-391.

9. Pinnock H, McKenzie L, Price D, Sheikh A. Cost-effectiveness of telephone or surgery asthma reviews: economic analysis of a randomised controlled trial. Br J Gen Pract 2005; 55(511): 119-124.

10. Wassen J, Gaudette C, Whaley F, et al. Telephone care as a substitute for routine clinic follow-up. JAMA 1992; 267(13): 1788-1793.

11. McKinstry B, Walker J, Campbell C, et al. Telephone consultations to manage requests for same-day appointments: a randomised controlled trial in two practices. Br J Gen Pract 2002; 52(477): 306-310.

12. Richards DA, Meakins J, Tawfik J, et al. Nurse telephone triage fo same day appointments in general practice: multiple interrupted time series trial of effect on workload and costs. BMJ 2002; 325(7374): 1214.

13. Katz SE, Kaltsounis D, Halloran L, Mondor M. Patient safety and telephone medicine. J Gen Intern Med 2008; 23(5): 517-522.

14. Information Services Division Scotland. General practice workforce information. Edinburgh: ISD Scotland, 2008. http://www.isdscotland.org/isd/information-andstatistics.jsp?pContentID=3793\&p_applic=CCC\&p_service=Conte nt.show\& (accessed 7 May 2009).

15. Strauss A, Corbin J. Basics of qualitative research. 2nd edn. London: Sage, 1998.

16. Kuzel A. Sampling in qualitative enquiry. In: Crabtree B, Miller W (eds). Doing qualitative research. Research methods for primary care. London: Sage, 1999: 33-46.

17. Steinberg A, Barnett S, Meador H, et al. Health care system access: Experiences and perceptions of deaf people. J Gen Intern Med 2006; 21(3): 260-266.

18. Wensing M, Vedsted P, Kersnik J, et al. Patient satisfaction with the availability of general practice: an international comparison. Qual Health Care 2002; 14(111): 118.

19. Hallam L. Access to general practice and GPs by telephone: the patient's view. Br J Gen Pract 1993; 43(373): 331-335.

20. Arber S, Sawyer L. The role of receptionists in general practice. A 'dragon behind the desk'? Soc Sci Med 1985; 20(9): 911-921.

21. Carstairs V, Morris R. Deprivation and health in Scotland. Health Bull 1999; 48(4): 162-175.

22. Hallam L. Patient access to general practitioners by telephone: the doctor's view. Br J Gen Pract 1992; 42(358): 186-189.

23. Hildebrandt DE, Westfall JM, Fernald DH, Pace WD. Harm resulting from inappropriate telephone triage in primary care. $J$ Am Board Fam Med 2006; 19(5): 437-442.

24. Bunn F, Byrne G, Kendall S. Telephone consultation and triage: effects on health care use and patient satisfaction. Cochrane Database Syst Rev 2004; 4: CD004180.

25. Armstrong D. Space and time in British general practice. Soc Sci Med 1985; 20(7): 659-666.

26. Pinnock H, Bawden R, Proctor S, et al. Accessibility, acceptability, and effectiveness in primary care of routine telephone review of asthma: pragmatic, randomised controlled trial. BMJ 2003; 326(7387): 477-479.

27. Simon GE, Ludman EJ, Tutty S, et al. Telephone psychotherapy and telephone care management for primary care patients starting antidepressant treatment: a randomized controlled trial. JAMA 2004; 292(8): 935-942. 


\section{Appendix 1. Response rate and demographic characteristics of questionnaire responders.}

Response Age in years, Sex, Ethnicity, rate, $n(\%) \quad$ mean (SD) \% male \% white

\begin{tabular}{lllll}
\hline GPs & $105 / 301(34.8)$ & $47(7.6)$ & 52 & 97
\end{tabular}

\begin{tabular}{lllll}
\hline Nurses & $107 / 304(35.2)$ & $47.6(7.0)$ & 4 & 100
\end{tabular}

Admin staff $143 / 305$ (46.8) $46.3(9.0) \quad 7 \quad 100$

Patients $\quad 227 / 600(37.8) \quad 52.3(16.7) \quad 32 \quad 98$
Appendix 2. Main uses of telephone consulting: percentage of GPs and nurses who say they use telephone consultations for various purposes.

\begin{tabular}{lcccccc}
$\begin{array}{c}\text { Screen } \\
\text { house } \\
\text { calls }\end{array}$ & $\begin{array}{c}\text { Screen } \\
\text { same-day } \\
\text { requests }\end{array}$ & $\begin{array}{c}\text { Consulting } \\
\text { for new } \\
\text { problems }\end{array}$ & $\begin{array}{c}\text { Follow-on } \\
\text { consultations }\end{array}$ & $\begin{array}{c}\text { Brief } \\
\text { advice }\end{array}$ & $\begin{array}{c}\text { Chronic } \\
\text { disease } \\
\text { management }\end{array}$ \\
\hline GPs & 38 & 39 & 46 & 54 & 89 & 25 \\
\hline Nurses & 17 & 20 & 14 & 21 & 42 & 15 \\
\hline
\end{tabular}

\section{Appendix 3. Percentage of responders who thought that patients from different groups may be disadvantaged by telephone consulting.}

\begin{tabular}{lcccccccc} 
& $\begin{array}{c}\text { Patient, English } \\
\text { not first language }\end{array}$ & $\begin{array}{c}\text { Doctor, English } \\
\text { not first language }\end{array}$ & Dementia & $\begin{array}{c}\text { Learning } \\
\text { difficulty }\end{array}$ & $\begin{array}{c}\text { Speech } \\
\text { difficulty }\end{array}$ & $\begin{array}{c}\text { Hearing } \\
\text { difficulty }\end{array}$ & $\begin{array}{c}\text { Older } \\
\text { person }\end{array}$ & \begin{tabular}{c} 
Anxious \\
\hline GPs
\end{tabular} \\
\hline Nurses & 85 & 61 & 93 & 78 & 83 & 84 & 21 & 3 \\
\hline Admin staff & 75 & 96 & 20 & 81 & 88 & 85 & 27 & 19 \\
\hline Patients & 68 & 81 & 19 & 70 & 75 & 85 & 24 & 7 \\
\hline
\end{tabular}

Appendix 4. Participants' views on suitability of conditions for telephone consulting.

\begin{tabular}{|c|c|c|c|c|c|c|c|c|c|c|c|c|}
\hline & \multicolumn{3}{|c|}{ GPs, \% } & \multicolumn{3}{|c|}{ Nurses, \% } & \multicolumn{3}{|c|}{ Patients, \% } & \multicolumn{3}{|c|}{ Admin staff, \% } \\
\hline & Never & $\begin{array}{l}\text { Yes, but } \\
\text { always } \\
\text { follow up }\end{array}$ & $\begin{array}{l}\text { Yes, but } \\
\text { follow up if } \\
\text { necessary }\end{array}$ & Never & $\begin{array}{l}\text { Yes, but } \\
\text { always } \\
\text { follow up }\end{array}$ & $\begin{array}{l}\text { Yes, but } \\
\text { follow up if } \\
\text { necessary }\end{array}$ & Never & $\begin{array}{l}\text { Yes, but } \\
\text { always } \\
\text { follow up }\end{array}$ & $\begin{array}{l}\text { Yes, but } \\
\text { follow up if } \\
\text { necessary }\end{array}$ & Never & $\begin{array}{l}\text { Yes, but } \\
\text { always } \\
\text { follow up }\end{array}$ & $\begin{array}{l}\text { Yes, but } \\
\text { follow up if } \\
\text { necessary }\end{array}$ \\
\hline Itchy skin rash & 12 & 38 & 51 & 39 & 32 & 29 & 18 & 30 & 52 & 29 & 45 & 27 \\
\hline $\begin{array}{l}\text { Results of } \\
\text { laboratory test }\end{array}$ & 1 & 8 & 90 & 3 & 19 & 78 & 8 & 19 & 72 & 1 & 10 & 90 \\
\hline $\begin{array}{l}\text { Cough, spit, and } \\
\text { temperature in adult }\end{array}$ & 17 & 33 & 50 & 36 & 43 & 21 & 21 & 36 & 42 & 19 & 45 & 35 \\
\hline $\begin{array}{l}\text { Abdominal pain } \\
\text { and diarrhoea }\end{array}$ & 21 & 34 & 45 & 34 & 36 & 30 & 16 & 37 & 47 & 40 & 41 & 18 \\
\hline Painful ankle injury & 37 & 30 & 34 & 64 & 21 & 15 & 23 & 34 & 43 & 15 & 40 & 46 \\
\hline $\begin{array}{l}\text { New severe } \\
\text { headache }\end{array}$ & 86 & 11 & 3 & 84 & 11 & 6 & 39 & 35 & 26 & 50 & 30 & 20 \\
\hline $\begin{array}{l}\text { Cough and } \\
\text { temperature in child } \\
<3 \text { years for }>24 \text { hours }\end{array}$ & 32 & 39 & 29 & 70 & 17 & 13 & 51 & 34 & 15 & 74 & 19 & 7 \\
\hline $\begin{array}{l}\text { Flare up of } \\
\text { rheumatoid arthritis }\end{array}$ & 28 & 51 & 21 & 39 & 52 & 9 & & & & & & \\
\hline $\begin{array}{l}\text { Asthma symptom } \\
\text { review }\end{array}$ & 19 & 42 & 39 & 17 & 37 & 46 & & & & & & \\
\hline $\begin{array}{l}\text { Left-sided chest } \\
\text { pain }\end{array}$ & 75 & 19 & 6 & 87 & 10 & 3 & & & & & & \\
\hline Epilepsy review & 15 & 23 & 62 & 24 & 37 & 39 & & & & & & \\
\hline $\begin{array}{l}\text { Recurrent episode } \\
\text { of depression }\end{array}$ & 45 & 44 & 11 & 61 & 32 & 7 & & & & & & \\
\hline $\begin{array}{l}\text { Suspected urine } \\
\text { infection in } \\
\text { adult female }\end{array}$ & 1 & 15 & 84 & 18 & 43 & 39 & & & & & & \\
\hline
\end{tabular}

apatients and administrative staff were only asked about the first seven conditions. 
Appendix 5. Percentage of responders agreeing or strongly agreeing on factors related to phone consultation compared with face-to-face consultation.

Concern about inaccurate Knowing clinician Telephone consulting diagnosis, \% improves confidence, \% improves continuity, \%

\begin{tabular}{llll}
\hline GPs & 70 & 95 & 95 \\
\hline Nurses & 75 & 78 & 78 \\
\hline Admin staff & 15 & 70 & 70 \\
\hline Patients & 58 & 75 & 75 \\
\hline
\end{tabular}

Appendix 6. Percentage of responders agreeing or strongly agreeing that patients may not understand or remember medical advice over the phone as much as face-to-face consultations.

\begin{tabular}{lcc} 
& May not understand, \% & May not remember, \% \\
\hline GPs & 35 & 25 \\
\hline Nurses & 42 & 43 \\
\hline Patients & 45 & 31 \\
\hline
\end{tabular}

Appendix 7. Percentage of responders who were aware of available telephone interpretive services in their practices for hearing impaired patients and those who do not speak English.

\begin{tabular}{lccc} 
& $\begin{array}{c}\text { Type talk } \\
\text { available, } \%\end{array}$ & $\begin{array}{c}\text { Interpretation service } \\
\text { available, \% }\end{array}$ & $\begin{array}{c}\text { Other systems in place to } \\
\text { aid disadvantaged patients, \% }\end{array}$ \\
\hline GPs & 15.2 & 26.7 & 9.5 \\
\hline Nurses & 15.0 & 16.8 & 21.5 \\
\hline Admin staff & 26.8 & 31.7 & 18.3 \\
\hline
\end{tabular}

